the consultant role might become more generic in nature, with the potential that this might compromise job satisfaction, as Pajak et al (2003) have shown that general adult psychiatrists demonstrate significantly lower levels of job satisfaction.

\section{Declaration of interest}

This project was funded by the Department of Health.

\section{References}

CALNAN, S., WAINWRIGHT, D. FORSYTHE, M., et al (2001) Mental health and stress in the workplace: the case of general practice in the UK. Socia Science and Medicine, 52, 499-507.

DEPARTMENTOFHEALTH (1996) Health Survey for England 1994. Department of Health.

DEPARTMENT OF HEALTH (2005) New Ways of Working for Psychiatrists:

Enhancing Effective, Person-Centred Services Through NewWays of Working in Multidisciplinary and Multiagency Contexts. Department of Health.

EDWARDS, D., BURNARD, P., HANNIGAN, B., et al (2000) Stressors, moderators and stress outcomes for community mental health nurses:

findings from the All Wales Community Mental Health Nursing Study. Journal of
Psychiatric and Mental Health Nursing, 7, 529-539.

GOLDBERG, D. (1992) General Health Questionnaire (GHQ-12). nferNelson.

KARASEK, R., BRISSON, C. KAWAKAMI, N., et al (1998) The Job Content Questionnaire (JCQ): an instrument for internationally comparative assessments of psychological job characteristics Journal of Occupational Health Psychology, 3, 322-355.

MASLACH, C. \& JACKSON, S. E. (1993) Manual of the Maslach Burnout Inventory (2nd edn). Consulting Psychologists Press.
MEARS, A., PAJAK, S., KENDALL,T., et al (2004) Consultant psychiatrists' working patterns: is a progressive approach the key to staff retention? Psychiatric Bulletin, 28, 251-253.

original papers

\footnotetext{
*Alex Mears Research Fellow, Royal College of Psychiatrists Research and Training Unit, Standon House, 21 Mansell Street, London E1 8AA, email: alex.mears@virgin.net, Sarah Pajak ResearchWorker, Tim Kendall Deputy Director, Royal College of Psychiatrists Research and TrainingUnit, Cornelius Katona Dean (1998-2003), Royal College of Psychiatrists, Jibby Medina Research Assistant, Royal College of Psychiatrists Research and Training Unit, Peter Huxley Professor of SocialWork , Sherrill Evans Research Coordinator, Claire Gately ResearchWorker, Institute of Psychiatry, London
}

\title{
Meeting NICE self-harm standards in an accident and emergency department
}

\author{
AIMS AND METHOD \\ An audit in a general hospital acci- \\ dent and emergency (A\&E) depart- \\ ment and the subsequent \\ development of a triage process for \\ people presenting with self-harm is \\ described. A random sample of 103 \\ people attending with self-harm \\ were selected and their treatment \\ audited against standards derived \\ from NICE guidelines.
}

\begin{abstract}
RESULTS
The service provided by the A\&E department was sub-standard. Of particular concern was the lack of processes addressing risk assessment and safe discharge. A pro forma was designed with the aim of improving assessment of self-harm. A repeat audit 3 months after introduction of the pro forma showed an improvement in the recording of relevant
\end{abstract}

\author{
information underpinning risk \\ assessment.

\section{CLINICAL IMPLICATIONS} \\ Procedures for those presenting to \\ A\&E departments with self-harm \\ may not meet recommended \\ guidelines. The use of a pro forma \\ with staff training can improve risk \\ assessment.
}

Dorset County Hospital is part of the West Dorset General Hospitals NHS Trust and is a modern hospital with 500 beds. The mean attendance rate of patients presenting with self-harm to the accident and emergency (A\&E) department is 46 patients a month. Psychiatric services are provided in partnership with a neighbouring trust.

Self-harm is an umbrella term for causing harm to oneself. Allen (1995) explores the difficulty with definition of this term, and describes a very wide range of methods that people use to hurt themselves, including scratching, cutting, stabbing, scalding, burning themselves or overdose of prescribed medication. The selfharm may or may not have suicidal intent.

Dealing with self-harm has been a national priority for some time (Department of Health, 1992, 2002). Those who harm themselves remain at a substantially increased level of completed suicide for some time after the episode of self-harm (Eastwick \& Grant, 2004). Self-harm accounts for 150000 attendances at general hospitals each year, and is one of the top five causes of acute medical admissions in the UK (Royal College of Psychiatrists, 2006; http://www.rcpsych.ac.uk/crtu/ centreforqualityimprovement/self-harmproject.aspx).

The National Service Framework for Mental Health (Department of Health, 1999) emphasised the need for a specialist psychosocial assessment following self-harm. The Royal College of Psychiatrists' view (2004) is that this can be done by trained A\&E personnel and doctors working in the A\&E department, although this has been debated by other authors (Hughes \& Owens, 1996; Cook, 1998). 
The National Institute for Health and Clinical Excellence (2004) published guidelines on self-harm, which

original papers give recommendations to improve care for people who self-harm to all professionals involved in their care. Among other standards, this report gives service standards for A\&E departments.

Simpson (2006) concludes that the NICE (2004) recommended that self-harm services needed to be reviewed as a matter or urgency, but Simpson considers that this is difficult to do inside an organisation where the term self-harm itself presents ambiguity; continuing that many of the recommendations made had to be differentiated between people that had presented with self-harm and those applicable to individuals that had attempted self-poisoning. Also difficulties arise where there exists prejudice from nurses towards people who self-harm. Owens (2006) also argues about the accuracy of psychosocial assessments and risk assessments in the A\&E department and details the flaws in trying to meet the guidelines.

Lyons et al (2000) report that suicide risk assessment is an important part of the nurse's role and should be systematic. Some identified risk factors in suicide include being unmarried, being unemployed, living alone, poor physical health/chronic pain, previous self-harming behaviour, loss events (health, person, cherished idea, material possession), mental illness, substance use and suicidal behaviour in first-degree relatives (Cheng et al, 2000).

The problems in developing tools to support clinical decision-making after a person has self-harmed are the subject of a recent paper from the Manchester group (Cooper et al, 2006), and Lyons et al (2000) write that a one-off scoring system does not reflect the dynamic nature of suicidal behaviour.

Barr et al (2004) suggest that there is evidence that people presenting with self-harm are considerably likely to self-discharge or abscond. Pennycook et al (1992) report that $4 \%$ of all patients attending an A\&E department self-discharged, with the most common medical diagnosis being self-poisoning.

This paper uses the results of a broad clinical audit to consider how well patients with self-harm presenting to the A\&E department were managed. A pro forma to improve standards was designed and a repeat audit carried out to investigate the outcomes.

\section{Method}

A working group led by N.K. was formed to look at how Dorset County Hospital managed people that presented with self-harm. The working group included an A\&E consultant, a lead from the audit department of Dorset County Hospital and a dual-trained nurse (mental health and adult; L.H.). There were three main areas for investigation, although only the first will be examined in this paper:

- an audit of patient's casualty notes over the previous 6 months (May 2004 to November 2004) to establish how well the NICE guidelines were met

- a questionnaire study examining training of staff at Dorset County Hospital, knowledge about self-harm and staff attitudes and values underpinning the care given and confidence levels in managing self-harm

- Patient satisfaction with the care they received.

\section{Initial audit}

There were 380 patients with self-harm that attended the A\&E department from May 2004 to November 2004. At random L.H. extracted the data from 103 A\&E notes from this population. The audit examined patients' notes with a clinical coding of 'DSH', 'deliberate self-harm', 'overdose', 'self-poisoning' and 'accidental overdose', as well as 'depressed'. Any notes with 'accidental overdose' were dismissed. The standards used were derived from those in the NICE guidance (2004), and included the documentation of capacity, willingness to stay for treatment, circumstances of self-harm, mood, presence or absence of apparent mental disorder, and use of a formal risk assessment (i.e. the use of a structured tool or the clear identification of key risk factors).

As a result of this first audit, a pro forma was designed (see data supplement to online version of this paper) and included an adapted version of the Australian mental health triage process, as indicated in the NICE (2004) guidelines. There was broad local discussion to promote ownership of this new tool, with comments sought from A\&E doctors and nurses and mental health services. The risk assessment process chosen for the pro forma was that used by the local intensive psychiatric care unit. Although there is no research evidence base for its use, this was felt to promote local consistency, and

Table 1. Emergency department practice on standards of risk assessment and its documentation

Documentation of

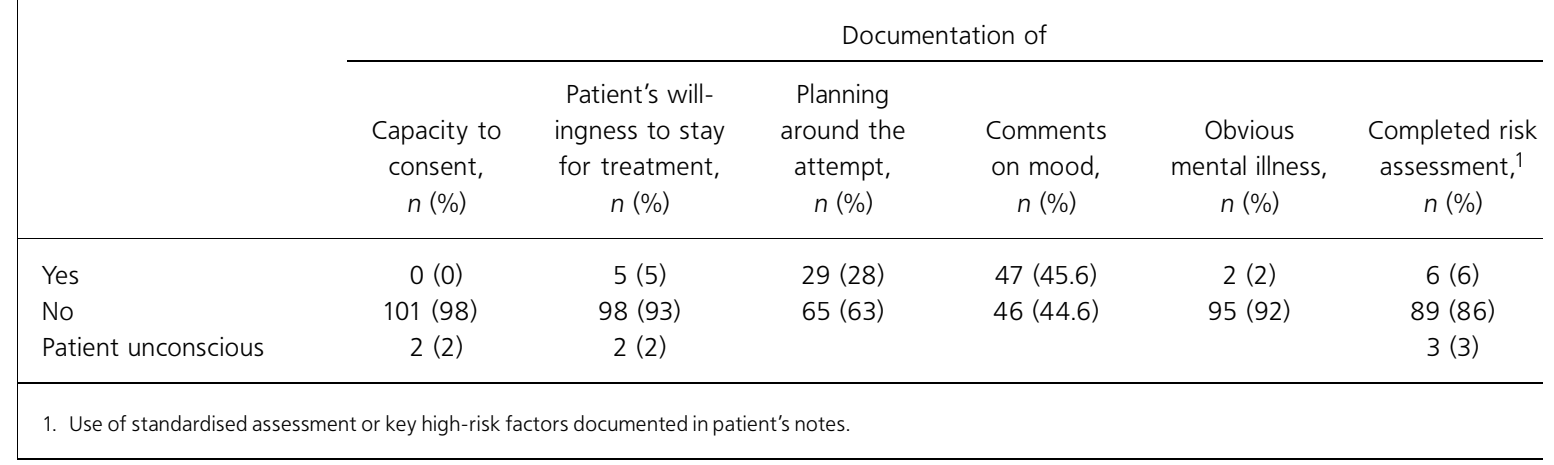


Table 2. Emergency department practice on parameters of care

\begin{tabular}{lc} 
& $\begin{array}{c}\text { Patients, } \\
n(\%)\end{array}$ \\
\hline How long did the patient wait before initial & \\
assessment? & \\
$\leq 15 \mathrm{~min}$ & $79(76)$ \\
$16-30 \mathrm{~min}$ & $8(8)$ \\
$31-45 \mathrm{~min}$ & $3(3)$ \\
$46-60 \mathrm{~min}$ & $1(1)$ \\
$>60 \mathrm{~min}$ & $1(1)$ \\
Patient self-discharged & $1(1)$ \\
Not documented & $10(10)$ \\
Outcome for patients & \\
Home & $16(16)$ \\
Admitted to West Dorset General Hospital & $22(21)$ \\
Psychiatric team (either seen in department & $20(19)$ \\
or referred for future assessment) & \\
Self-harm worker & $3(3)$ \\
Crisis response (out-of-hours team) & $19(18)$ \\
Police & $1(1)$ \\
Prison & $3(3)$ \\
Community Alcohol Drug Advisory Service & $1(1)$ \\
Self-discharged & $13(13)$ \\
Not documented & $5(5)$ \\
\hline
\end{tabular}

the process appears to have high face validity. A system was also developed whereby the pro forma was printed automatically with casualty notes that had an initial clinical coding of 'overdose', 'deliberate self-harm' or 'selfpoisoning'.

All staff working in the A\&E department received a written training package, including a presentation on basic mental health assessment, psychiatric terminology and some information on capacity to consent, prior to the pro forma being introduced.

The pro forma was initially trialed over a 3-month period, then a repeat audit was carried out on 100 consecutive people attending with self-harm. The staff completing the pro forma did not know that an audit was being carried out.

\section{Results}

\section{Initial audit}

Table 1 shows the practice at the A\&E department on various standards regarding risk assessment and its documentation.

Table 2 shows some of the parameters of care. Most patients were seen quickly ( $84 \%$ within $30 \mathrm{~min}$ ). The most common initial disposal was assessment by psychiatric services (40\%), with $21 \%$ being admitted to a medical or surgical ward. However, $16 \%$ were sent home without specialist assessment and 13\% self-discharged before being assessed.

\section{Repeat audit}

Table 3 gives results before and after the introduction of the pro forma.
Table 3. Emergency department practice before and after introduction of pro forma

\begin{tabular}{|c|c|c|}
\hline Factor assessed & $\begin{array}{l}\text { Before } \\
\text { pro forma }\end{array}$ & $\begin{array}{c}\text { After } \\
\text { pro forma }\end{array}$ \\
\hline \multicolumn{3}{|c|}{ Capacity to consent documented, \% } \\
\hline Yes & 0.0 & 91.0 \\
\hline No & 98.0 & 8.0 \\
\hline Patient unconscious & & 1.0 \\
\hline \multicolumn{3}{|c|}{$\begin{array}{l}\text { Patient's willingness to stay for } \\
\text { treatment documented, } \%\end{array}$} \\
\hline Yes & 4.8 & 87.0 \\
\hline No & 93.0 & 11.0 \\
\hline Patient unconscious & & 2.0 \\
\hline \multicolumn{3}{|l|}{$\begin{array}{l}\text { Any obvious mental illness } \\
\text { documented, \% }\end{array}$} \\
\hline Yes & 2.0 & 74.0 \\
\hline No & 92.0 & 24.0 \\
\hline Patient unconscious & & 2.0 \\
\hline \multicolumn{3}{|l|}{ Australian triage used, \% } \\
\hline Yes & NA & 97.0 \\
\hline No & NA & 3.0 \\
\hline Patient unconscious & NA & 1.0 \\
\hline \multicolumn{3}{|c|}{$\begin{array}{l}\text { Did patient get discharged without } \\
\text { being seen by specialist services in the } \\
\text { emergency department, \% }\end{array}$} \\
\hline Yes & 28.0 & 43.0 \\
\hline No & 23.0 & 57.0 \\
\hline \multicolumn{3}{|c|}{$\begin{array}{l}\text { Comments on patient's mood } \\
\text { documented, \% }\end{array}$} \\
\hline Yes & 45.6 & 92.0 \\
\hline No & 44.6 & 7.0 \\
\hline Patient unconscious & 2.9 & 1.0 \\
\hline \multicolumn{3}{|c|}{ Risk assessment completed 1 , \% } \\
\hline Yes & 5.8 & 97.0 \\
\hline No & 86.4 & 2.0 \\
\hline Patient unconscious & 2.9 & 1.0 \\
\hline \multicolumn{3}{|c|}{$\begin{array}{l}\text { Patient's past psychiatric and medical } \\
\text { history documented, } \%\end{array}$} \\
\hline Yes & NA & 75.0 \\
\hline No & NA & 25.0 \\
\hline Patient unconscious & NA & \\
\hline \multicolumn{3}{|c|}{$\begin{array}{l}\text { Treatment plan documented on the } \\
\text { designated form, \% }\end{array}$} \\
\hline Yes & NA & \\
\hline No & NA & 70.0 \\
\hline Patient unconscious & NA & 30.0 \\
\hline
\end{tabular}

NA, not available

1. Use of standardised assessment or key high-risk factors documented in the patient's notes.

\section{Discussion}

The results of the first audit suggest that the A\&E department was falling below identified standards in some areas of practice, especially on risk assessment and arrangements for safe discharge.

The pro forma that was subsequently designed allows A\&E clinicians to make informed choices about appropriate treatment by helping them to discriminate between patients at higher and lower risks. Cooper et al original papers 
(2006) have shown that a simple screening tool can work in an A\&E department to highlight those patients at high risk and in need of a more specialist assessment by a

original papers trained mental health professional. They also report that the assessment is for short-term risk only.

The value of this new approach helped to challenge attitudes and cemented engagement. Nurses' attitudes can stand in the way of following the NICE guidelines (Simpson, 2006). McCann et al (2006) agree that A\&E nurses frequently have negative attitudes and lack appropriate assessment and interpersonal skills to care for individuals who self-harm.

The results of the secondary audit suggest that the introduction of the self-harm pro forma improved the frequency of formal risk assessment and the documentation of important risk factors. It appears to be associated with a reduction in the frequency of patients discharging themselves before assessment and an increase in the number having specialist psychosocial assessment. Clinical implications are that the introduction of a relatively simple tool and consequent change in clinical process following work designed to improve local ownership can lead to an apparent improvement in clinical care for patients.

\section{Limitations}

Audit of this nature is subject to criticism. It is unclear whether the 103 patients seen before the introduction of the pro forma were representative of the population attending the emergency department at that time, although it is likely that this was the case. In addition, populations studied before and after the introduction of the pro forma were not matched. However, the project time frame was fairly tight at 6 months and staff turnover during that period was minimal. One person completed data extraction using a consistent tool. It is of course possible that the training and greater exposure of staff to issues surrounding self-harm following the audit also improved practice on the parameters assessed, however we would argue that this is still desirable.

\section{Declaration of interest}

None.

\section{References}

ALLEN, C. (1995) Helping with deliberate self-harm, some practical guidelines. Journal of Mental Health, $\mathbf{4}$, $243-250$.

BARR, W., LEITNER, M. \& THOMAS, J. (2004) Self-harm patients who take early discharge from the accident and emergency department: how do they differ from those who stay? Accident and Emergency Nursing, 12 108-113.

CHENG, A.T. A., CHEN, T. H. H., CHEN,

C., et al (2000) Psychosocial and psychiatric risk factors for suicide: case-control psychological autopsy study. British Journal of Psychiatry, 177, 360-365.

COOK, A. (1998) Assessing deliberate self harm, a team approach. Emergency Nurse, 6, 21-24.

COOPER, J., KAPUR, N., DUNNING, J., et al (2006) A clinical tool for assessing risk after self-harm. Annals of Emergency Care, 48, 459-466.

DEPARTMENT OF HEALTH (1992) The Health of the Nation. TSO (The Stationery Office).

DEPARTMENT OF HEALTH (1999) National Service Framework for Mental Health. Department of Health.

DEPARTMENT OF HEALTH (2002) National Suicide Prevention Strategy for England. Department of Health.

EASTWICK, Z. \& GRANT, A. (2004) Emotional rescue: deliberate selfharmers and A\&E departments. Menta Health Practice, 7, 12-16.

HUGHES, T. \& OWENS, D. (1996)

Management of suicidal risk. British

Journal of Hospital Medicine, 56, 151 154

LYONS, C., PRICE, P., EMBLING, S., et al (2000) Suicide risk assessment: a review of procedures. Accident and Emergency Nursing, 8, 178-186.

MCCANN, T., CLARK, E,

McCONNACHIE, S., et al (2006) Accident and emergency nurses' attitudes towards patients who selfharm. Accident and Emergency Nursing, 14, 4-10.

NATIONAL INSTITUTE FOR CLINICAL EXCELLENCE (2004) Self-Harm. The Short-term Physical Management and Secondary Prevention of Self-Harm in Primary and Secondary Care. NICE.

OWENS, D. (2006) Services for assessment and aftercare following self-harm. Psychiatry, 5, 271-274.

PENNYCOOK, A., MCNAUGHTON, G. \& HOGG, F. (1992) Irregular discharge against medical advice from the accident and emergency department

- a cause for concern. Archives of Emergency Medicine, 9, 230-238. ROYAL COLLEGE OF PSYCHIATRISTS \& BRITISH ASSOCIATION FOR ACCIDENT

AND EMERGENCY MEDICINE (2004) Psychiatric Services to Accident and Emergency Departments (Council Report CR118). Royal College of Psychiatrists \& British Association for Accident and Emergency Medicine.

SIMPSON, A. (2006) Can mainstream health services provide a meaningful care for people who self-harm? A critical reflection. Journal of Psychiatric and Mental Health Nursing, 13, 429436.

*Leah Hughes Sister, Accident and Emergency/Crisis ResponseTriageWorker Dorset County Hospital, Dorchester, Dorset DT12JY, email: leah.hughes@ wdgh.nhs.uk, Nick Kosky Consultant Psychiatrist and Clinical Director of Dorset Primary CareTrust, Dorset County Hospital, Dorchester 